\title{
Futsal feminino na América do Sul: trajetórias de enfrentamentos e de conquistas
}

\author{
Helena Altmann* \\ Heloisa Helena Baldy dos Reis ${ }^{* *}$
}

\begin{abstract}
Resumo: Este artigo analisa as experiências com futebol de jogadoras de futsal de seleções nacionais de países da América do Sul. Foram realizadas entrevistas com 16 jogadoras de seis países em 2009. Conclui-se que elas se constituíram como jogadoras a partir da prática informal do futebol em companhia de homens. Para jogar, elas precisaram dominar habilidades futebolísticas e enfrentar barreiras sociais que relacionam o futebol e aquelas que o praticam ao masculino. Todas destacam a falta de estrutura esportiva nos seus países, no entanto, o Brasil é visto como tendo uma estrutura privilegiada para esse esporte.
\end{abstract}

Palavras-chave: Futebol feminino. Futsal. Gênero. América do Sul.

\section{INTRODUÇÃO}

Este artigo tem com objetivo analisar as experiências com futebol de jogadoras de futsal de seleções nacionais de países da América do Sul. Considerando que as seleções nacionais são compostas pelas principais atletas de seus respectivos países, nosso objetivo foi analisar como essas jogadoras de alto rendimento iniciaram sua prática e como o vivenciam no atual momento da carreira. O local de iniciação a este esporte, sua prática na escola, o

\footnotetext{
"Professora da Faculdade de Educação Física, Universidade de Campinas, Campinas, SP, Brasil. E-mail: altmann@fef.unicamp.br

"Professora da Faculdade de Educação Física, Universidade de Campinas, Campinas, SP, Brasil. E-mail: helobaldy@yahoo.com
} 
apoio social recebido quando iniciantes, as dificuldades enfrentadas e as conquistas atingidas são pontos aqui analisados. Sob uma perspectiva de gênero ${ }^{1}$, analisamos a trajetória de jogadoras bem sucedidas em um esporte que, durante muitos anos, esteve vinculado, e relativamente restrito, ao universo masculino. Além disso, a análise de dados obtidos com jogadoras de diferentes países possibilita a comparação de experiências na América do Sul, constatando-se mais semelhanças do que diferenças entre os países no que se refere aos aspectos analisados. Outrossim, entendemos que esse artigo vai ao encontro de outras pesquisas com outros grupos sociais e em outros momentos históricos (GOELLNER, 2005, MORAES, 2012, MOURA, 2003, SILVEIRA; STIGGER, 2009) e contribui para dar visibilidade à prática do futsal feminino na América do Sul².

Neste artigo, são analisadas entrevistas realizadas com jogadoras das seleções de seis países durante o II Campeonato SulAmericano Feminino de Futsal, organizado pela Confederação Brasileira de Futsal e Confederación Sudamericana de Fútbol, realizado na Universidade Estadual de Campinas, em setembro de 2009. Foram feitas entrevistas individuais com 16 jogadoras de futsal, assim distribuídas: cinco jogadoras do Brasil, três do Uruguai, três do Peru, duas da Bolívia, duas da Argentina e uma da Colômbia. A

\footnotetext{
'Embora este artigo não tenha como objetivo realizar uma análise teórica do conceito de gênero, trata-se de "um conceito desenvolvido para contestar a naturalização da diferença sexual em múltiplos terrenos de luta." (HARAWAY, 1995). Utilizado pela primeira vez por Gael Rubin, em 1975, sua consolidação no campo acadêmico é mais recente, sendo o texto de Scott (1995), originalmente publicado em 1988, um marco importante na utilização deste conceito no campo das ciências humanas, da educação e da própria educação física. Scott (1995) define gênero como uma categoria analítica que concebe as diferenças entre homens e mulheres, os femininos e os masculinos como processos de construção histórica e social. Ele se articula com outras categorias, como raça, classe, geração, sexualidade, entre outras, sendo uma forma de dar significado às relações de poder. Atualmente, além de um conceito, gênero constitui-se um campo de produção de conhecimento (MATOS, 2008), com intensa articulação com questões ligadas à sexualidade. Outros referenciais de gênero importantes para este artigo são Louro (1999), Nickolson (2000), Piscitelli (2002).

${ }^{2}$ A legislação de 1941, não permitia que mulheres praticassem esportes "incompatíveis com sua natureza", sem explicitar quais esportes eram esses (BRASIL, 1941). Já em 1965, a prática de lutas de qualquer natureza, futebol, futebol de salão, futebol de praia, polo aquático, rugby, halterofilismo foram proibidas (BRASIL, 1965, CASTELLANI FILHO, 1988, ROSEMBERG, 1995). Não obstante, a necessidade de criar legislações que proibissem determinadas práticas esportivas é um indício do interesse das mulheres por essas modalidades. Sobre as trajetórias de mulheres no judô no Brasil, vide Souza e Mourão (2011).
}

Movimento, Porto Alegre, v. 19, n. 03, p. 211-232, jul/set de 2013. 
realização das entrevistas foi inicialmente autorizada pelos técnicos das seleções e depois pelas jogadoras, escolhidas aleatoriamente, que assinaram um termo de consentimento livre e esclarecido antes do início das mesmas. Se, por um lado, a realização desta competição internacional, reunindo um grande número de atletas de diferentes países, constituiu um rico espaço de pesquisa, por outro, o controle das equipes técnicas sobre as jogadoras, neste período de jogos, também dificultou o acesso a um maior número de jogadoras e uma maior disponibilidade de tempo para as entrevistas. Além da realização das entrevistas, que são analisadas neste artigo, foi aplicado um questionário com questões fechadas a todas as jogadoras. A Seleção Brasileira foi a única que se negou a responder ao questionário, alegando que enviaria as respostas posteriormente, o que não ocorreu. Tais aspectos mostram um pouco das dificuldades encontradas para a realização de pesquisas com atletas de alto rendimento.

As jogadoras entrevistadas tinham entre 21 e 44 anos, sendo que as duas jogadoras mais velhas (34 e 44 anos), cujas idades diferenciam-se das demais, jogam futebol de campo no exterior Estados Unidos e Itália. Esse fato indica a consolidação e o prolongamento da carreira como jogadoras de futebol obtido pela saída do próprio país. Muitas das 16 jogadoras entrevistadas jogam tanto futebol de campo quanto futsal e há uma goleira brasileira que iniciou sua carreira no handebol, tendo desse migrado por falta de patrocínio.

As entrevistas foram realizadas nas línguas de origem das jogadoras, sendo posteriormente transcritas e, quando o caso, traduzidas para o português.

As jogadoras brasileiras são as únicas que recebem remuneração para jogar neste momento da carreira, embora não sejam registradas como atletas profissionais. Elas recebem bolsas de seus clubes e do governo brasileiro para jogar, além de bolsa de estudo em cursos universitários. Uma uruguaia, atualmente residente nos Estados Unidos, tem no futebol sua fonte de renda, mas agora não mais como jogadora, como ocorreu no passado, mas ensinando futebol a crianças. Esses dados já indicam algo também presente 
nas falas das jogadoras: o Brasil diferencia-se dos demais países da América do Sul por apresentar uma melhor estrutura no futsal feminino de alto rendimento. Esta conclusão será retomada em outro momento deste artigo.

Nesta competição, a equipe do Brasil consagrou-se campeã, vencendo a segunda colocada, Colômbia, por sete gols a um. A equipe da Venezuela ficou em terceiro lugar, seguida do Peru e da Argentina. $\mathrm{O}$ resultado final da competição e da partida final, indica certa superioridade do Brasil nesta modalidade em relação aos demais países.

\section{INICIAÇÃO AO FUTEBOL ${ }^{3}$}

Sem nenhuma exceção, essas jogadoras começaram a jogar futebol com meninos, quando tinham entre 3 e $11 \operatorname{anos}^{4}$. Sua iniciação esportiva no futebol ocorreu na companhia de homens, tais como irmãos, amigos, primos, vizinhos e pais. A rua é o espaço mais mencionado por elas como local onde jogavam bola, seguida da própria casa quando o jogo ocorria com familiares. Os irmãos foram a principal companhia dessas mulheres, com quem, junto com outros amigos, se apropriavam de espaços públicos para jogar futebol. A iniciação a esse esporte ocorreu de forma informal, entre pares, em espaços públicos como a rua e quadras ou no quintal da própria casa. Elas partilhavam dessa experiência futebolística com meninos, sem a companhia de outras meninas, e sem a intervenção de algum profissional do ramo.

Essa situação assemelha-se a dados encontrados por outras pesquisas com jogadoras brasileiras. Ao pesquisar a história de vida de jogadoras do interior baiano, que jogaram futebol entre 1970 e 1990, Enny Moraes (2012) mostra a inexistência de um projeto institucionalizado de formação de base das jogadoras e afirma que

\footnotetext{
${ }^{3}$ Futebol é tratado aqui como jogos de bolas com os pés. Nas entrevistas não foram especificados se eram rigorosamente jogos de futsal ou futebol de campo, no entanto, pelos depoimentos apreende-se que se tratava de jogos de bola com os pés.

${ }^{4} \mathrm{Em}$ média, elas tinham 7,3 anos.
} 
para iniciarem essa prática, muitas vezes tiveram que fazê-la driblando o impedimento dos pais, que consideravam o futebol uma atividade eminentemente masculina. Assim, as meninas logo tiveram que se acostumar ao codinome macho-feme, termo usual nessas cidades baianas, que se refere às meninas/os que são um misto de mulher-homem/ homem-mulher (MORAES, 2012, p. 24).

No próximo item deste artigo, retomaremos essa adjetivação masculina do futebol e de quem o pratica. No que se refere à iniciação a esse esporte, Eriberto Moura (2003), em pesquisa com seis exjogadoras de futebol de campo da equipe do Guarani Futebol Clube de Campinas (1983-1984), constata que duas iniciaram sua prática de futebol com 10 anos de idade, uma com menos de dez anos, uma com cinco anos, uma com onze anos e outra com 15 anos. Dentre elas, apenas uma teve sua iniciação em uma escola e com participação apenas de meninas. Em todos os outros casos a iniciação deu-se em espaços de lazer em grupos mistos e de idades variadas, incluindo, em alguns casos, homens adultos (MOURA, 2003).

Já, em Santana e Ribeiro (2010), que pesquisaram 97 jogadoras de futsal feminino com média de idade de 23,93 $( \pm 5,4)$ anos $^{5}$, de oito equipes da $8^{\mathrm{a}}$ Liga Nacional de Futsal no Brasil, a idade média de iniciação foi de 10,6 anos $( \pm 3,8)$ na prática sistemática e de 12,4 anos $( \pm 3,5)$ em competições federadas.

Ainda que o instrumento utilizado pelos autores não as tenha questionado sobre a prática informal, como é o caso da nossa pesquisa, trazer os dados da iniciação sistemática de jogadoras de futsal nos permite uma visão da iniciação neste esporte pelas crianças e adolescentes no Brasil. Entre as jogadoras pesquisadas por Santana e Ribeiro (2010), a maioria (55,6\%) iniciou sua prática regular no futsal com mais de 10 anos de idade, seguidos de um grupo $(25,8 \%)$ com idade entre cinco e sete anos e de outro grupo $(18,5 \%)$ que iniciou entre oito e nove anos de idade.

\footnotetext{
${ }^{5} \mathrm{~A}$ idade varia 5,4 anos para mais ou para menos, quer dizer: a jogadora de menor idade tinha 18,5 anos e a de maior idade 29,3 anos.
} 
Outro aspecto é que, se inicialmente nossas entrevistadas enfrentavam certa resistência por parte dos meninos para jogar, a demonstração de suas habilidades futebolísticas garantia-lhes espaço e status perante o grupo, conforme explicitado na fala de duas jogadoras:

"No começo eles não queriam deixar: eles falavam
'menina não sabe jogar', e isso e aquilo. Mas depois
que eles deixaram eu jogar a primeira vez, eu sempre
fui a primeira a ser escolhida no time. Eles sempre
queriam que eu estivesse no time deles." (Sílvia,
Brasil, 25) . "Ao invés de chamar meu irmão pra $_{\text {jogar, eles vinham e me chamavam" (Joana, Brasil, }}$
21).

A boa habilidade esportiva também aparece como critério de inclusão de meninas em jogos de futebol em outras pesquisas. Altmann (1998), em seu estudo que incluiu alunos e alunas brasileiras de $5 .^{\text {a }}$ série (atual $6 .^{\circ}$ ano) do ensino fundamental, com idades entre 11 e 15 anos, discorre sobre a exclusão nos esportes e aponta não ser o gênero o único motivo de exclusão nas aulas de educação física e nos esportes. Em seu estudo, a autora observou que apesar de os meninos, em média, participarem dos jogos mais do que as meninas, tanto quantitativa como qualitativamente, podia-se notar meninas que tinham um nível de participação próximo ao dos meninos e vice-versa. A boa habilidade com o futebol de algumas meninas garantia sua participação efetiva nos jogos de futebol, enquanto a menor ou falta de habilidade futebolística de alguns meninos, gerava sua exclusão ou não participação dessa prática.

Em outra pesquisa no espaço escolar, Liane Uchoga (2012) também observou que meninas mais habilidosas participavam de forma mais efetiva das atividades práticas nas aulas de educação física. As meninas com boas habilidades futebolísticas também relataram a prática de jogos de bola em espaços informais, na companhia de outros meninos.

${ }^{6}$ Os nomes das jogadoras são fictícios, seguidos de sua nacionalidade e idade.

Movimento, Porto Alegre, v. 19, n. 03, p. 211-232, jul/set de 2013. 
A experiência de ter jogado com meninos é vista pelas jogadoras da nossa pesquisa como algo extremamente positivo, que trouxe vantagens para a aprendizagem desta modalidade esportiva. Por serem considerados mais fortes, habilidosos e experientes com o futebol, jogar com meninos proporcionou a aquisição de habilidades futebolísticas diversas, ensinou-as a jogar mais rápido - habilidade importante no futsal -, bem como garantiu uma evolução mais rápida dentro do esporte.

"(Jogar com os meninos) foi uma experiência boa, porque eu acho que a evolução da menina é melhor. Quando a gente está no meio dos meninos, a gente melhora, porque se a gente fosse começar a jogar no meio de outras meninas talvez a gente não conseguisse evoluir, porque as meninas, querendo ou não, não tem tanta força física, é diferente. Jogando entre os meninos você se desenvolve mais rápido." (Irene, Brasil, 22)

"Aprendi muito com os meninos, porque os meninos são mais fortes e jogam forte." (Débora, Uruguai, 34) (grifos nossos)

Essa constatação da vantagem do convívio com homens para a aprendizagem do futebol também foi constatada por Moraes (2012) e Moura (2003).

Além disso, nossas entrevistadas destacam outra aprendizagem obtida por essa socialização com meninos. Mesmo que essa aprendizagem não seja algo inerente ao futebol, ela é vista como sendo de suma importância, sendo apontada como fruto da experiência com meninos: jogar com meninos ensinou-as a ser fortes.

"Era interessante (jogar com meninos) porque pelo fato de ser uma menina, aparentemente mais delicada, aprendi a ser forte, muito forte, então me ajudou bastante." (Renata, Bolívia, 29)

"(Eu e meu primo) saíamos para jogar. Ele me batia, me chutava, eu chorava, mas, ele dizia, 'não chore ou não te levo mais para jogar'. Então ele me fez ser forte. Eu ficava calada porque queria seguir jogando. (Ligia, Peru, 24) (grifos nossos)

Movimento, Porto Alegre, v. 19, n. 03, p. 211-232, jul/set de 2013. 
Diferentemente do observado em outras pesquisas, com jogadoras de um menor nível técnico e tático, como dentro de escolas (ALTMANN, 1998, CLARK; PAECHTER, 2007, UCHOGA, 2012) e escolas de futebol (VIANA, 2012), estas jogadoras de seleções nacionais revelam ter enfrentado menos dificuldade na prática do futebol com meninos. Os poucos conflitos de gênero mencionados foram contornados através da comprovação de suas habilidades futebolísticas e de sua "força" para enfrentar embates, a dor e o jogo em si.

No geral, a escola não foi mencionada de forma espontânea pelas atletas entrevistadas como um local de prática do futebol. Isso já mostra sua menor importância na aprendizagem futebolística. No entanto, a partir de perguntas específicas formuladas pelas entrevistadoras, oito jogadoras mencionaram que jogavam futebol na escola ${ }^{7}$. Diferentemente da rua e do espaço doméstico, na escola, outras meninas também jogavam. As aulas de educação física são o espaço mais mencionado por elas como um local escolar onde jogavam futebol, tendo sido mencionado por seis jogadoras, seguido da participação em campeonatos esportivos, citado por três, e, em menor medida, dos recreios, apenas duas.

Dentro da escola, as aulas de educação física configuram-se no principal espaço de aprendizagem e vivência do futebol, mostrando sua importância dentro desse contexto. Todavia, o principal local onde essas jogadoras de futsal iniciaram sua formação como jogadoras não foi a escola, nem as aulas de educação física, nem escolas de futebol. Elas se constituem jogadoras de futebol por meio de práticas na rua, no bairro, no quintal, na companhia de meninos, sejam eles irmãos, amigos, vizinhos ou primos. A iniciação esportiva das principais atletas de futsal de países sul americanos ocorre de maneira informal, não institucional e sem intervenção especializada.

${ }^{7}$ Cinco jogadoras disseram que não jogavam futebol na escola e três não fizeram menção a tal aspecto. 


\section{Apolo social para a pRática do fUtebol}

As jogadoras de futsal entrevistadas revelam terem recebido apoio para a prática do futebol ao longo da sua trajetória. Apenas três jogadoras informaram não terem recebido nenhum apoio, sendo que duas delas enfatizaram terem sido elas próprias suas maiores incentivadoras. Entre aquelas que receberam apoio, o apoio da família é o mais mencionado, principalmente através do pai, citado por oito jogadoras. Também foram mencionados irmãos, mãe, avô e primo. Além de membros da família, três atletas citaram amigos como incentivadores e apenas uma, seu professor de educação física ${ }^{8}$.

"Minha família sempre me apoiou no futsal. Gostam sempre de assistir quando tem jogos. Eu não tive dificuldades em relação a isso. [...] Minha mãe me deu incentivo." (Sílvia, Brasil, 25)

"Eu acho que meu pai foi quem me incentivou. Quando ele morreu, essa coisa ficou em mim, tinha paixão pelo futebol. Depois, minha professora de educação física sempre me apoiou e me incentivou em geral para o esporte e me fez muito bem." (Débora, Uruguai, 34)

Como resposta à pergunta "Tem alguém que lhe incentivou a jogar?", Camila (Uruguai, 21) respondeu:

"Não, mais do que eu, ninguém. Ou seja, agora tenho mais apoio da minha família, que veem que eu gosto, que é o que realmente quero fazer e apoiam ao máximo. [...] Agora me apoiam amigos e minha família, mas quando eu era criança, ninguém. Fui eu sozinha."

Conforme pode ser visto na transcrição abaixo, a jogadora Daniela conquistou o apoio do pai depois que esse percebeu seu apreço pela modalidade. A resistência da mãe foi superada mais tardiamente, quando ela percebeu novas oportunidades trazidas pelo futebol na carreira da filha.

\footnotetext{
${ }^{8}$ Esses relatos diferem-se do preconceito enfrentado dentro de casa por outras jogadoras profissionais. Marta, por exemplo, revelou que "corria para não apanhar do irmão mais velho, pois ele não se conformava em vê-la jogando futebol" (GRACIANO, 2008).
} 
"Cresci vendo os meninos jogar. Eu também queria jogar e aí percebi que eu gostava. Porque eu deixava de fazer minhas tarefas, de ira uma festa, qualquer coisa para ir jogar futebol. Aí meu pai falou: 'Bom, se você gosta de futebol, se dedica, disciplinadamente, futebol, futebol, futebol.'. Parei de sair para balada, sair para dançar, para beber e coisas assim. Dediquei-me a treinar e fazer vida de esportista. Meu pai sempre esteve aí comigo, embora minha mãe no começo não gostava muito, porque dizia: 'Para que você vai jogar futebol? Os vizinhos vão falar que você é machona. É jogo de homens, você não tem que jogar.'. E meu pai não, ele me dizia para jogar futebol."

\section{[...]}

"Hoje minha mãe não fala mais nada, porque demonstrei que jogar futebol não quer mais dizer ser homem. É um esporte que, com disciplina e ordem, tem muitas coisas bonitas e abre portas para muitas coisas. Um dos meus objetivos - e de toda a seleção - foi ter aberto portas para a universidade." (Daniela, Peru, 23)

As falas de algumas atletas indicam que, de modo semelhante à aceitação por parte dos meninos jogadores, o apoio social à prática do futebol está em grande parte condicionado à demonstração de sua competência esportiva. Assim, não é através de algum apoio para a prática de futebol que elas passam a jogá-lo. O processo ocorre de forma inversa. Elas começam a jogar futebol por iniciativa própria, na companhia de meninos de idades próximas a elas, e posteriormente recebem apoio social para continuar jogando. Esse apoio surge após a percepção de seu destaque no futebol, ou seja, elas primeiro precisam comprovar sua competência esportiva no futebol, para então receberem apoio.

Em uma pesquisa que analisou os treinos e as relações de gênero dentro de uma escola de futebol franqueada do município de Campinas, Aline Viana (2012) observou um maior apoio social aos meninos do que às meninas para o treinamento. Enquanto muitos familiares levavam seus filhos ao campo e acompanhavam da 
arquibancada treinos e campeonatos, as meninas chegavam sozinhas à escola de futebol e não contavam com pessoas próximas que as assistissem.

$\mathrm{Na}$ pesquisa com as jogadoras sul-americanas, é possível observar que, de um modo geral, o apoio social à prática do futebol não ocorre durante a iniciação esportiva, mas depois que certo nível de habilidade futebolística já foi construído. Além disso, esse apoio social recebido é individual e particular, mais do que coletivo, governamental ou institucional. Neste aspecto, o Brasil diferenciase significativamente em relação aos demais países. Conforme já mencionado na introdução, no atual momento da carreira, as jogadoras da seleção brasileira de futsal entrevistadas usufruem de condições de treino e prática qualitativamente muito superiores às jogadoras dos demais países, como treinos diários e o recebimento de bolsas. No entanto, também no Brasil, este apoio recebido no momento ápice da sua carreira não se mostrou presente no período de iniciação esportiva e de sua consolidação como atletas.

Ao se referirem à torcida durante o campeonato, uma jogadora brasileira afirmou: "Eu acho que foi a maior torcida que já vi até hoje incentivando." (Irene, Brasil, 22). Sua fala mostra que nem sempre seus jogos são acompanhados por um grande público, o que também explicita certo desinteresse da torcida por competições femininas.

Por outro lado, ainda que o apoio recebido seja restrito, a percepção positiva em relação a ele mostra-se superior quando comparado com pessoas não atletas. Em que pese as diferenças regionais e metodológicas, se compararmos esses dados à percepção de apoio social à prática de esportes e outras práticas corporais de estudantes de ensino fundamental da região metropolitana de Campinas, encontramos resultados bastante distintos. Entre essas estudantes dos dois últimos anos do Ensino Fundamental, a percepção de apoio social é baixa. Os(as) professores(as) de educação física são tidos como seus principais incentivadores, seguido de amigos(as) e por último de familiares (ALTMANN et. al, 2011). Esta ordem é completamente inversa da encontrada entre as atletas, em que familiares são os principais incentivadores, seguido de 
amigos(as). Professores(as) de educação física são mencionados por apenas uma jogadora. Deste modo, enquanto com estudantes de escolas, os(as) professores(as) de educação física são os principais incentivadores à prática de esportes e atividade física, seguidos dos amigos e por último da família, entre as principais atletas de futsal no Brasil e na América do Sul, a relação é exatamente inversa, pois em primeiro lugar vem a família, depois os amigos e por último professores(as).

Se comparássemos os dados dessas duas pesquisas só com as respostas das atletas de futsal brasileiras, teríamos a mesma diferença. A comparação entre os resultados destas pesquisas indica que o apoio social da família é importante para a consolidação de uma atleta de alto rendimento.

Também a maioria das jogadoras entrevistadas na pesquisa de Souza Junior e Reis $(2012)^{9}$ revela receber apoio dos familiares. No entanto, foi muito recorrente no discurso dessas entrevistadas a mudança de opinião das mães, passando de uma desaprovação inicial para uma aceitação. Há um aspecto em comum entre essas duas pesquisas: o apoio familiar à prática do futebol feminino é uma conquista das jogadoras e não um ponto de partida.

\section{MULHERES EM CAMPO: DRIBLANDO EXPECTATIVAS E PRECONCEITOS DE GÊNEROEDE SEXUALDADE}

Em suas análises, Moraes (2012) mostra como a inserção da mulher no futebol foi se construindo de forma silenciosa e paulatina, enfrentando barreiras de várias ordens, muitas delas ligadas ao gênero e à sexualidade:

A inserção da mulher em alguns espaços sociais, como os esportes considerados de domínio dos homens, deu-se devido à sua constante luta transplantando barreiras e preconceitos. No caso

\footnotetext{
9SOUZA JUNIOR, Osmar Moreira; REIS, Heloisa Helena Baldy. O canto das sereias: o futebol como atividade "profissional" no Estado de São Paulo. In: KESSLER, Cláudia S. Mulheres na área: gênero, diversidade e inserções no futebol. (no prelo).
} 
do futebol nacional, ainda considerado como uma reserva masculina, ideia reforçada pela medicina e pela biologia que consideravam sua prática imprópria para mulheres, uma das estratégias forjadas com base nas convenções sociais foi definir a mulher praticante de futebol como lésbica, ou seja, fora dos padrões da normalidade sexual, como forma pejorativa de identificá-la, estigmatizando e rotulando historicamente essas jogadoras. (MORAES, 2012)

É possível observar na citação acima, bem como em outras passagens subsequentes deste artigo, uma estratégia discursiva sobre a sexualidade das jogadoras, que sofre um controle social no sentido de normalizá-la. Tal qual formulado por Michel Foucault (1997), a sexualidade é aqui compreendida como um dispositivo histórico elaborado na sociedade ocidental moderna por meio de um conjunto heterogêneo de saberes, práticas, instituições e discursos. A partir do século XVIII, o sexo foi colocado em discurso em nossa sociedade, produzindo-se uma verdade sobre ele, que é também tida como uma verdade sobre os sujeitos. Em torno do sexo desenvolveu-se uma complexa tecnologia de administração da vida individual e coletiva da população.

A recorrente associação socialmente estabelecida nos países sul-americanos, conforme demostraremos a seguir, entre a prática do futebol por mulheres e a homossexualidade é uma estratégia discursiva que busca normalizar tanto o gênero quanto a sexualidade, demarcando o futebol como não condizente com determinadas expectativas em relação ao gênero e à sexualidade femininos. Encontramos aí regimes discursivos de normatividade (BRITZMAN, 1996, BUTLER, 2003) dentro da instituição esportiva. Aclassificação, ou mesmo a reincidente suspeita, de que mulheres que jogam futebol são homossexuais e o uso disso como forma de constrição social, são concepções socialmente construídas que se legitimam através de uma falsa naturalidade. Trata-se de uma prática discursiva no sentido de exercer controle sobre as mulheres, seja no que se refere à experiência esportiva, seja ao gênero e à sexualidade. As falas 
das jogadoras e as análises desenvolvidas nesta pesquisa evidenciam que a comprovação da sua habilidade futebolística é uma forma de resistir a esta estratégia de controle e normalização social.

No início dos anos 2000, uma das jogadoras entrevistada por Moura (2003, p. 69-70), ao ser indagada sobre a existência ou não de preconceitos, declarou: "Era até interessante quando fazíamos um gol então, tinham os elogios: gostosa! Mas quando você fazia uma jogada errada ... vai para a cozinha! vai lavar a roupa! Vai ficar com o seu marido!" Tal depoimento demonstra as contradições às quais as jogadoras estão sujeitas: elogios a uma ação bem executada em campo são atravessados pela erotização do corpo feminino, enquanto a repreensão por uma ação mal sucedida demarca o local da mulher como sendo o espaço privado no qual deve desempenhar tarefas domésticas e cuidar do marido. Essa forma de comunicação entre o público e as jogadoras está atravessada de significados de gênero que exercem poder em relação ao lugar social da mulher. $\mathrm{O}$ bom desempenho neste esporte é condição indispensável não apenas para a atuação dentro de campo, mas também para sua aceitação social.

As declarações de outra jogadora, entrevistada por Moura (2003), demonstraram esse mesmo aspecto, no entanto, acrescido de um novo elemento: a possibilidade de esse preconceito ser também exercido por outras mulheres. "No começo, a gente entrava no campo, o pessoal xingava, chamava de 'sapatão', de 'vagabunda', de tudo o que se possa imaginar: 'Vai lavar a roupa', essas coisas assim. Então, o preconceito era grande. Depois é que passou a ter um respeito maior. Muitas mulheres tinham também preconceito, pois quando você falava que jogava futebol, muitas te olhavam 'torto' e achavam que você era 'sapatão'." (MOURA, 2003, p. 70)

$\mathrm{Na}$ nossa pesquisa, a principal dificuldade mencionada pelas jogadoras sul-americanas quando começam a jogar futebol diz respeito à percepção do futebol como um esporte masculino e à consequente vinculação das meninas que jogam à masculinidade ou à homossexualidade. No trecho de entrevista transcrito a seguir, o campo de futebol é delimitado como sendo um local inadequado a 
mulheres através da vinculação da imagem daquelas que o praticam a homossexualidade, buscando estabelecer assim um simultâneo controle de gênero sobre seus corpos e sua sexualidade.

"Quando jogávamos na rua não (tinha preconceito), porque eram amigos, família, não tinha problema. Mas depois, jogando no torneio entre bairros sim: insultos, diziam que não era para mulheres, falavam para me dedicar a outra coisa, chamavam-nos de 'machão', de 'homens'. [...] Diziam varias coisa, que não deveríamos jogar futebol porque é coisa de homens. Mas faz um tempo que não há, agora é mais tranquilo jogar futebol." (Renata, Bolívia, 29)

A jogadora brasileira Marta Vieira da Silva, escolhida como melhor futebolista do mundo por cinco vezes consecutivas, viveuexperiência similar, como pode ser visto no relato do seu primeiro técnico de futebol, José Júlio de Freitas:

(Marta) se destacava tanto em campo que chegaram a suspeitar de sua sexualidade. O técnico de um time rival, irritado com o talento da então adolescente sugeriu que ela deveria tirar a roupa na frente dos outros para ver se era realmente do sexo feminino. [...] Precisei engrossar com os caras para não fazerem aquele absurdo. (SGARIONI, 2011, p. 38)

Com o passar do tempo, a fim de evitar "humilhações", jogar no time de Marta tornou-se objeto de disputa: "Ninguém gostava do fato de ela ser mulher - e muito menos perder para uma mulher. Então o jeito era se juntar a ela. E era uma briga, todos os meninos queriam Marta no time." (SGARIONI, 2011, p. 38)

A jogadora de futsal Camila (Uruguai, 21), ao falar sobre a experiência de jogar com meninos quando criança, afirma que às vezes "sacaneavam", como chamando de "machinho" e comenta: "Coisas normais de uma mulher jogar futebol." Depois explica que isso foi apenas no início da carreira e que agora não enfrenta esses problemas. Já Débora (Uruguai, 34) - que posteriormente tornou-se jogadora nos Estados Unidos - afirma: "Eu sempre continuei jogando, sem dar muita atenção às coisas que me falavam.". 
Embora essas jogadoras resistam à percepção social do futebol como prática masculina e ao uso desse imaginário como forma de estigmatizá-las e constrange-las a não jogar, simultaneamente também naturalizam diferenças entre homens e mulheres. Tal aspecto está presente na fala de Camila, citada acima, mas de forma ainda mais intensa, na fala de uma jogadora colombiana transcrita abaixo:

"Acredito que não só na Colômbia [as mulheres enfrentam preconceito por jogar futebol]. Existe ainda esse preconceito, esse receio porque as mulheres jogam futebol. As pessoas pensam que o futebol é só para homens, mas não. Tem mulheres que, sem perder nossa essência, que somos mulheres, somos femininas, jogam de igual a igual, com qualquer país, e até podemos jogar contra homens e a diferença não é muita. Só que nós não deixamos de ser mulheres por jogar futsal." (Nara, Colômbia)

Marcar sua experiência como jogadoras de futebol pelo feminino parece ser uma estratégia adotada por várias jogadoras de modo a dizimar o principal preconceito por elas enfrentado na sua trajetória futebolística. Explorar e expor a beleza das jogadoras apresenta-se como um recurso para feminizar a experiência com o futebol e construir um novo lugar de mulher em campo:

"Sempre tem (preconceito). A gente sofre muito com isso, até (com) pessoas da família [...]: "mulher tem que pilotar fogão". [...] Hoje em dia está melhorando. Mas ainda existe e tem que ser diferente, porque mulher também pode praticar esporte "masculino", entendeu? Não tem que ser, 'ah, só homem pode jogar e mulher só vôlei', não é isso. E a gente está conseguindo ultrapassar esta barreira. Tem também, algumas meninas que fazem este preconceito crescer, quer cortar o cabelo curto, arrepiar, andar igual homem, e não é bem assim. Não é porque pratica um esporte masculino, que você vai se masculinizar também. Eu prefiro me ajeitar, jogo sempre de faixinha..." (Joana, Brasil, 21) (grifos nossos) 


\section{Considerações FinaIS}

No contexto desta pesquisa, verificou-se que as atletas de futsal da América do Sul constituíram-se jogadoras a partir da prática informal do futebol. Durante a infância, suas primeiras experiências futebolísticas ocorreram na companhia de homens, familiares ou amigos, na maioria, crianças como elas. O início dessa prática ocorreu de forma autônoma, sem incentivo externo e vencendo fronteiras de gênero e de sexualidade que demarcaram o futebol como uma experiência masculina. Sua aceitação pelos grupos de pares foi decorrente da comprovação da habilidade futebolística, a qual também lhes garantiu um status de igualdade em campo. Essa experiência esportiva com homens é destacada como positiva, seja no que se refere à aquisição de habilidades técnico-táticas, seja no que se refere à aprendizagem da superação da dor, dos conflitos e das dificuldades do jogo. Sua socialização com meninos através do futebol distanciaas da fragilidade em campo, educando-as para a força e para a competitividade, qualidades importantes para a prática desse esporte.

É também sua consagração como jogadoras habilidosas que garante sua posterior aceitação extracampo, como entre familiares e professores ou perante a torcida. Assim, o incentivo à prática do futebol por pessoas adultas ou por instituições não foi um ponto de partida para que elas tenham se tornado jogadoras, mas algo conquistado pela sua prática e por seus movimentos de resistência. Em outras palavras, o incentivo para jogar futebol surgiu delas mesmas e na sua convivência com outros meninos. Quando ocorre, o apoio social é posterior, quando já alcançaram um nível esportivo que as distingue positivamente das demais meninas e, segundo o olhar de alguns, aproxima-as futebolisticamente dos meninos.

Assim, as experiências com futebol das jogadoras sulamericanas entrevistadas ocorreram em um universo ainda predominantemente masculino, acompanhadas de meninos, pais, professores e técnicos. Essa experiência só passou a ser partilhada com outras meninas e mulheres posteriormente, dentro de um sistema esportivo precário que limita seu crescimento no esporte. 
Todas destacam a falta de estrutura esportiva nos seus próprios países, como ausência ou carência de campeonatos, de equipes e de tempo para treino, a não profissionalização do esporte, entre outros. O Brasil é visto pelas jogadoras dos demais países como tendo uma estrutura privilegiada para a prática do futsal feminino, com campeonatos, prática regular, treinamento e apoio financeiro às atletas. Para elas, é isso que produz a superioridade no futsal feminino brasileiro na América do Sul. Embora já tenham enfrentado problemas com a estrutura esportiva, no atual momento da carreira, as jogadoras brasileiras não expressaram viver dificuldades desta ordem. Sair do próprio país para jogar futebol é visto, por muitas delas, como uma oportunidade de realizar plenamente uma carreira no futsal ou no futebol de campo, fato este que se tornou realidade para duas jogadoras, uma na Itália e outra nos Estados Unidos da América. Assim, de acordo com as jogadoras entrevistadas nessa pesquisa, o Brasil, quando comparado com os demais países da América do Sul, possui uma estrutura esportiva superior para o futsal feminino.

Por fim, a experiência com o futebol também lhes exige enfrentar barreiras sociais que masculinizam o futebol e aquelas que o praticam. Jogar futebol na América do Sul significa driblar o estereótipo de jogadora homossexual, construindo novas possibilidades de ser mulher na sociedade contemporânea, as quais incluem o futebol como uma experiência de vida possível e legítima também às mulheres. Com a bola nos pés, elas driblam também fronteiras, obstáculos, estereótipos, preconceitos construindo novas formas de ser mulher jogadora de futebol. 


\section{Futsal Women in South America: coping} trajectories and achievements

Abstract: This article examines the experiences with football players of futsal national teams from countries in South America. Interviews were conducted with 16 players from six countries in 2009. We conclude that they constituted themselves as players from the informal practice of football in the company of men. To play, they had to master football skills and tackle social barriers that relate to football and those who practice it with masculinity. All highlight the lack of sports infrastructure in their countries, however, Brazil is seen as having a privileged structure for this sport.

Key words: Football woman. Futsal. Gender. South of America.

Futsal femenino de América del Sur:
trayectorias de afrontamiento y logros
Resumen: Este artículo examina las experiencias con
las jugadoras de futsal de las selecciones nacionales
de futsal de los países de América del Sur. Entrevistas
se llevaron a cabo con 16 jugadores de seis países
en 2009 . Llegamos a la conclusión de que se
constituyeron como jugadoras con la práctica informal
de fútbol en compañía de los hombres. Para jugar,
tenían que dominar las habilidades del fútbol y hacer
frente a las barreras sociales que se relacionan con
el fútbol y las que practican con el masculino. Todos
ponen de manifiesto la falta de infraestructura
deportiva en sus países, sin embargo, Brasil es visto
como una estructura privilegiada para este deporte.
Palabras Ilave: Fútbol femenino. Futsal. Género.
América del Sur.




\section{REFERÊNCIAS}

ALTMANN, Helena. Rompendo fronteiras de gênero: marias (e) homens nas quadras. 1998. Dissertação (Mestrado em Educação) - Universidade Federal de Minas Gerais, Belo Horizonte, 1998.

ALTMANN, Helena et. al. 2011. Educação física escolar e igualdade de gênero: um estudo transcultural, relatório de pesquisa. Campinas, 2011.

BRASIL. Decreto lei n. 3199 de14 de abril de 1941. Estabelece as bases de organização dos desportos em todo o país. 1941. Disponível em: <http:// www.planalto.gov.br>. Acesso em: 2012.

BRASIL. Conselho Nacional de Desportos. Deliberação n. 7 de agosto de 1965. Disponível em: <http://www.planalto.gov.br>. Acesso em: 2012.

BRITZMAN, Deborah. O que é essa coisa chamada amor, identidade homossexual, educação e currículo. Educação e Realidade, Porto Alegre, v. 21, n. 1, p. 71-96, jan./jun. 1996.

BUTLER, Judith. Problemas de gênero: feminismo e subversão da identidade. Rio de Janeiro: Civilização Brasileira, 2003.

CASTELLANI FILHO, Lino. Educação Física no Brasil: a história que não se conta. Campinas: Papirus, 1988.

FOUCAULT, Michel. A história da sexualidade. 12. ed. Tradução de Maria Thereza da Costa Albuquerque e J.A. Guilhon Albuquerque. Rio de Janeiro: Graal, 1997. v. 1: A vontade de saber.

GOELLNER, Silvana. Mulheres e futebol no Brasil: entre sombras e visibilidades. Revista Brasileira de Educação Física e Esporte. São Paulo, v. 19, n. 2, p. 143151, ab./jun., 2005.

GRACIANO, Diego. Você é mulher, Marta! São Paulo: All Print, 2008.

CLARK, Sheryl; PAECHTER, Carrie. Why can't girls play football? Gender dynamics and the playground. Sport, Education and Society, Londres, v. 12, n. 3, p. 261276, Aug, 2007.

HARAWAY, Donna. Gênero para um dicionário marxista: a política sexual de uma palavra. Cadernos Pagu, Campinas, n. 22, p. 201-246, jan./jun. 2004.

LOURO, Guacira Lopes. Gênero, sexualidade e educação: uma perspectiva pós-estruturalista. Petrópolis: Vozes, 1999. 
MATOS, Marlise. Teorias de gênero ou teorias e gênero? Se e como os estudos de gênero e feministas se transformaram em um campo novo para as ciências. Revista Estudos Feministas, Florianópolis, v. 16, n. 2, ago. 2008. Disponível em http:// www.scielo.br/scielo.php? script=sci_arttext\&pid=S0104026X2008000200003\&lng=pt\&nrm=iso. Acesso em: 27 jul. 2009.

MORAES, Enny Vieira. As mulheres também são boas de bola: histórias de vida de jogadoras baianas (1970-1990). 2012. Tese (Doutorado em História) Pontifícia Universidade Católica de São Paulo, São Paulo, 2012.

MOURA, Eriberto José Lessa de. As relações entre lazer, futebol e gênero. 2003. Dissertação (Mestrado em Educação Física) - Faculdade de Educação Física, Universidade Estadual de Campinas, Campinas, 2003.

NICKHOLSON, Linda. Interpretando o gênero. Revista Estudos Feministas, Florianópolis, v. 8, n. 2, p. 9-41, 2000.

PISCITELLI, Adriana. Re-criando a (categoria) mulher? In: ALEGRANTI, Leila Mezan. (Org.). A prática feminista e o conceito de gênero. Campinas: IFICH/UNICAMP, 2002. Disponível em: <http://www.pagu.unicamp.br/sites/www.pagu.unicamp.br/ files/Adriana01.pdf >. Acesso em: 23 fev. 2012.

ROSEMBERG, Fúlvia. A educação física, os esportes e as mulheres: balanço da bibliografia brasileira. In: ROMERO, Elaine. (Org.). Corpo, mulher e sociedade. Campinas: Papirus, 1995. p. 271-308.

SANTANA, W. C. de; RIBEIRO, Danilo, Augusto. Idades de início de atletas de futsal de alto rendimento na prática sistemática e em competições federadas da modalidade. Pensar a Prática, Goiânia, v. 13, n. 2, p. 117, maio/ago. 2010.

SCOTT, Joan. Gênero: uma categoria útil de análise histórica. Educação \& Realidade, Porto Alegre, v. 12, n. 2, p. 71-94, jul./dez. 1995.

SGARIONI, M. Muito além do gênero. Fut Lance, Rio de Janeiro, n. 28, p. 38, mar. 2011.

SILVEIRA, Raquel da; STIGGER, Marco P. Futsal feminino e o gerenciamento da (in)visibilidade da homossexualidade. In: SEMINÁRIO CORPO, GÊNERO E SEXUALIDADE, 4., Rio Grande, 2009. Anais... Rio Grande: 2009. p. 1-10.

SOUZA, Gabriela C.; MOURÃO, Ludmila. Mulheres no tatame: o judô feminino no Brasil. Rio de Janeiro: Mauad X, 2011.

RUBIN, Gale. The traffic in women: notes on the political economy of sex. In: REITER, Rayana. Toward an Anthropology of Women. New York: Monthly Review, 1975. p. 157-210. 
UCHOGA, Liane R. Educação física escolar e relações de gênero: risco, confiança, organização e sociabilidades em diferentes conteúdos. 2012. Dissertação (Mestrado em Educação Física) - Faculdade de Educação Física, Universidade Estadual de Campinas, Campinas, 2012.

VIANA, Aline E. As relações de gênero em uma escola de futebol: quando o jogo é possível. 2012. Dissertação (Mestrado em Educação Física) - Faculdade de Educação Física, Universidade Estadual de Campinas, Campinas, 2012.

Endereço para Correspondência

Helena Altmann

Universidade Estadual de Campinas

Faculdade de Educação Física

Departamento de Educação Física e Humanidades

Av. Érico Veríssimo, 701 - Cidade Universitária

Caixa Posta 6134

13083-851 - Campinas, SP - Brasil

Heloisa Helena Baldy dos Reis

Universidade Estadual de Campinas

Faculdade de Educação Física

Departamento de Ciências do Esporte

Av. Érico Veríssimo, 701 - Cidade Universitária

Caixa Posta 6134

13083-851 - Campinas, SP - Brasil

Recebido: 08.11.2012

Aprovado: 25.04.2013

Movimento, Porto Alegre, v. 19, n. 03, p. 211-232, jul/set de 2013. 